\title{
El derecho a la ciudad. Transformaciones y resistencias en la ciudad neoliberal.
}

\section{The right to the city. Transformations and resistance into the neoliberal city.}

\author{
TIPO DE TRABAJO: \\ Comunicación virtual. \\ PALABRAS CLAVE: \\ Glocal, espacio público, ciudad neoliberal, Cabanyal, ciudadano prosumidor.
}

KEY WORDS:

Glocal, public space, neoliberal city, Cabanyal, prosumer citizen.

\section{RESUMEN}

El arte puede actuar como bisagra sobre la idea de pensar globalmente y actuar localmente. Máxima acuñada en el Foro Social Mundial de Porto Alegre de 1999. Esta idea es un punto de partida que supone la base de los procesos de investigación y reflexión que nos proponemos. Articulado sobre la obra "Cabanyal 1641" esta comunicación explora la idea de ciudad enunciada desde las nuevas fórmulas ligadas al desarrollo del sector terciario, el control del espacio público y las nuevas estrategias del mercado capitalista que tienden a convertir lo público en espacio privado. Nuevas fórmulas de generar contenidos (sociales, espaciales, urbanísticos, etc.) de una manera in vitro, es decir, como una reproducción mimética de una realidad construida y despersonalizada que nos engloba en un todo. Estos procesos también generan resistencias, desde la protesta y los movimientos ciudadanos locales. Se trata de procesos híbridos que generan nuevas fórmulas de entender la cultura y de practicarla, por eso aparecen nuevas tribus urbanas, nuevas planificaciones urbanísticas y nuevos espacios geográficos que nos demuestran que la presunta neutralidad de su epistemología no es real. Al mismo tiempo y para concluir, señalar como los productores culturales tenemos la responsabilidad de proponer una transformación en la figura pasiva del ciudadano consumidor a ciudadano prosumidor. Es decir, en la capacidad de transformar una ciudadanía con una implicación más directa sobre el control de sus vidas.

\section{ABSTRACT (En inglés)}

Art can act as a hinge on the idea of thinking globally and acting locally. Maximum coined at the World Social Forum of Porto Alegre, 1999. This idea is a starting point that is the basis of the research and reflection processes that we propose. Articulated on the work "Cabanyal 1651" this communication explores the idea of a city enunciated from the new formulas linked to the development of the tertiary sector, the control of public space and the new strategies of the capitalist market that tend to turn public into private space. New formulas to generate contents (social, spatial, urban, etc.) in an in vitro way, that is, as a mimetic reproduction of a built and depersonalized reality that encompasses us into a whole. These processes also generate resistance, from protest and local citizen movements. These are hybrid processes that generate new formulas to understand the culture and to practice it, that is why new urban tribes, new urban planning and new geographical spaces appear that demonstrate to us that the supposed neutrality of its epistemology is not real. At the same time and to conclude, to point out as cultural producers we have the responsibility of proposing a transformation in the passive figure of the consumer to citizen prosumer. That is, in the capacity to transform a citizenship with a more direct involvement in the control of their lives. 


\section{CONTENIDO.}

\section{Introducción.}

Los gestos que los gobiernos tienen sobre nuestras ciudades en materia de políticas públicas suponen otro giro a la concepción capitalista de los derechos sobre la ciudad. Este artículo lo desarrollaremos centrándonos en primer término en dos ciudades, Londres y Grenoble, precisamente porque tienen propuestas totalmente opuestas. Así, podremos poner algunos ejemplos de como nuestras ciudades se han ido transformando y cómo según qué tendencias siguen podemos hacer un entorno más amable y más implicado en la ciudadanía, que no responda únicamente a necesidades financieras. Por último hablaremos del barrio del Cabanyal en la ciudad de Valencia para reflexionar sobre lo que expondremos a continuación con una intervención artística.

La ciudad, escribió una vez el sociólogo urbano Robert Park:

Es uno de los intentos más consistentes, y más exitosos del hombre, de rehacer el mundo en que vive a partir de sus deseos más profundos. Si la ciudad, en todo caso, es el mundo que el hombre ha creado, es también el mundo en que está condenado a vivir. Así, de manera indirecta y sin una conciencia clara de la natura de su trabajo, al hacer ciudad, el hombre se rehace a si mismo ${ }^{1}$.

David Harvey ${ }^{2}$, tomando la idea del derecho a la ciudad que manifestó Lefebvre, introduce el concepto derecho en la ciudad como fundamental, donde no se trata simplemente el derecho de acceso al que ya no existe, sino el derecho a cambiarlo a partir de nuestras inquietudes. El derecho a rehacernos a nosotros mismos creando un entorno urbano cualitativamente diferente es de los más preciados de los derechos humanos, por lo cual tenemos que formularnos la pregunta de cómo podemos ejercer mejor el derecho en la ciudad. La ciudad no ha sido nunca un lugar armónico, libre de confusión, conflictos o violencia. Sin embargo, la ciudad también ha demostrado ser una forma social notablemente elástica, duradera e innovadora. Marx, igual que el anteriormente citado Park, pensaba que nos cambiamos a nosotros mismos cambiando el mundo y viceversa. Esta relación dialéctica está arraigada en el mismo punto de todo el trabajo humano donde la imaginación y el deseo tienen un papel importante. Individual y colectivamente hacemos ciudad mediante nuestras acciones cotidianas y nuestro compromiso político, intelectual y económico sin perder de vista que la ciudad también nos hace a nosotros.

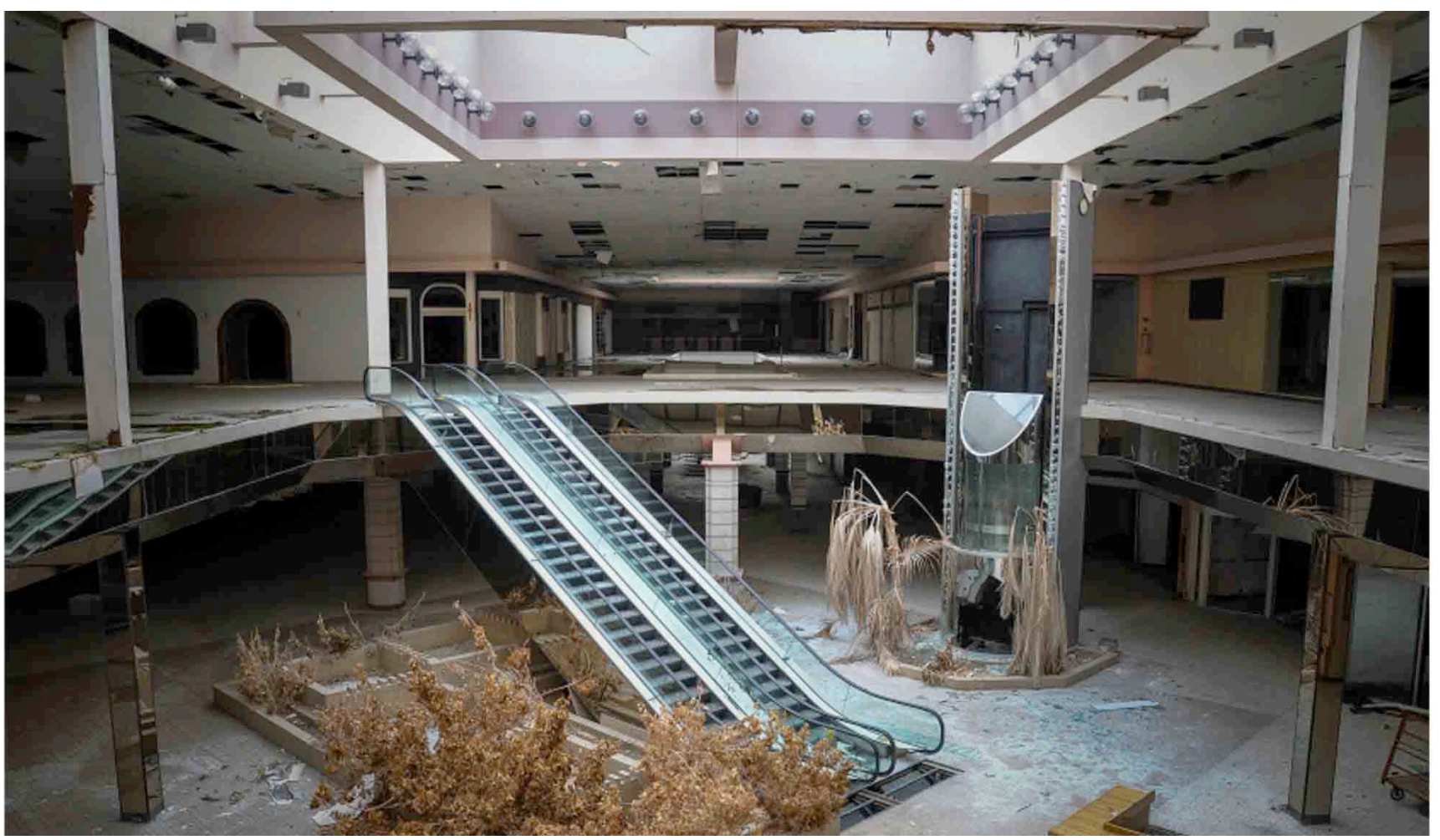

Ilustración 1. Centro comercial abandonado en Detroit, Estados Unidos.

\footnotetext{
${ }^{1}$ Harvey, David. El derecho a la Ciudad. Consultado En: http://www.sinpermiso.info/textos/index.php?id=2092-- (2/09/2014 a las 10.26 h). ${ }^{2}$ Harvey, David. Ciudades Rebeldes. Del derecho de la ciudad a la revolución urbana. Ed. Akal, Madrid, 2013. Pág. 20.
} 
Vivimos en una sociedad en que los derechos inalienables a la propiedad privada y los beneficios se imponen sobre cualquier otra concepción de derechos inalienables que se pueda tener. El libre mercado no es necesariamente justo, como dice un antiguo dicho: «no hay nada más desigual que el igual trato entre desiguales» ${ }^{3}$. Sin embargo, no podemos prescindir ni de los planes utópicos ni de los ideales de justicia, indispensables para la motivación y la acción. Todos los ideales en materia de derechos presuponen una cierta concepción de los procesos sociales y la inversa, todo proceso social incorpora alguna concepción de los derechos. El derecho activo a hacer una ciudad diferente, adecuada cada vez a las demandas sociales y a rehacernos también nosotros, según una imagen diferente. La creación de nuevos espacios urbanos comunes, de una esfera pública con participación democrática activa, requiere remontar la enorme tendencia de privatización en que estamos metidos, producida por el neoliberalismo. La ciudad tendría que ser más inclusiva, aunque siempre conflictiva ya que el continua estado de cuestionamiento es lo que la permite avanzar.

El jueves 5 de diciembre de 2013 Núria Álvarez Lombardero escribía el artículo «El espacio público neoliberal. La desaparición del espacio social» ${ }^{4}$ donde comenta como recientemente y a consecuencia de la crisis, los periódicos del Estado español han resaltado las consecuencias de las reformas realizadas por el gobierno en las dos últimas legislaturas que tienen que ver con el uso de las políticas económicas neoliberales. La Ley del Suelo, por ejemplo, aprobada el 1998, abrió las puertas a la especulación sobre el valor del suelo y el crecimiento de la vivienda, considerada una de las causas de la actual crisis. Sin embargo, una de las consecuencias del liberalismo que más afectará nuestras ciudades es la privatización del espacio público. La privatización de los servicios públicos es otro punto fuerte donde los agentes privados tienden a ser más productivos y eficaces. El Estado reduce su papel para ser más eficiente y permitir que el sector privado sea el encargado de generar riqueza. Esta cuestión se ha traducido en la ciudad en una progresiva privatización del espacio público, al considerarse que el Estado ya no puede hacerse cargo del mantenimiento de estos lugares. El capital privado pasa a hacerse cargo del espacio público y se convierte en propiedad privada a pesar de estar abierta el uso de todos los ciudadanos.

\section{Desarrollo.}

La coproducción del espacio público que incorpora estos agentes privados es un fenómeno que ha ido estableciéndose en los centros urbanos de ciudades europeas, así como en otras ciudades del resto del mundo, principalmente durante los años 80 y 90 , y que continúan en nuestros días. Esto supone un fenómeno de homogeneización de los centros de las ciudades a medida que los estados van aceptando las actuaciones propias del neoliberalismo.

Empezamos a encontrar ejemplos cercanos cómo sería el caso de Madrid, donde ya se está especulando con la transformación de plazas como la Puerta del Sol en centros de ocio programados. En este caso particular se han levantado algunas suspicacias puesto que la Puerta del Solo fue el lugar emblemático de las protestas ciudadanas del movimiento indignado en 2011 y el centro neurálgico del movimiento $15 \mathrm{M}$. Por eso, la autora analiza lo que ha ocurrido en otros espacios públicos de ciudades que ya adoptaron estas medidas anteriormente cómo es el caso de Londres, la ciudad neoliberal por excelencia.

Desde el gobierno de Margaret Tatcher (1979-1990) diferentes espacios públicos de la ciudad de Londres tienen en común una definición espacialmente determinada para la construcción de complejos privados de uso mixto diseñados bajo una arquitectura corporativa: edificios destinados a contener oficinas, bancos, etc., y con un diseño productivo de los edificios a gran escala y poco personalizados. Sería el caso del antiguo puerto de Canary Eharf, que aconteció el nuevo centro financiero de la ciudad y donde se construyeron diferentes torres de oficinas y centros comerciales que concentraban la actividad diaria. Únicamente dejaron un espacio residual de uso público altamente vigilado por cámaras de seguridad. El resultado es un espacio público muerto eclipsado por las grandes torres que la componen, sin actividad en el exterior y controladas por la propiedad privada ${ }^{5}$. Otro caso en el centro de Londres es la plaza Paternoster Square, situada en el barrio financiero de City. A partir de 1980, cuando la zona entró en decadencia, se decidió hacer una renovación urbana mediante una promoción privada a una empresa inmobiliaria. La idea era crear un espacio central público donde se abrirían los diferentes edificios diseñados por algunos arquitectos con el fin de acontecer propiedad del sector privado relacionado con el mundo corporativo. ${ }^{6}$ Se convertía así el antiguo centro de la ciudad en una versión corporativista y ocupada por varias empresas que progresivamente fue rechazado por los londinenses, principalmente por las construcciones monolíticas que las rodeaban y el alto nivel de vigilancia que imposibilita cualquier actividad no planeada. Por su carácter representativo del poder económico esta plaza fue elegida por los activistas de Occupy London el 2011, pero el bloqueo de acceso y la gran presencia policial evitaron finalmente la ocupación. Esta acción evidencia como una plaza que repetidamente se había presentado como un espacio público ha significado en realidad la necesidad de tener un permiso de acceso a la plaza con la posibilidad de ser restringido por sus propietarios en cualquier momento.

\footnotetext{
${ }^{3}$ Harvey, David. El derecho a la Ciudad. Consultat En: http://www.sinpermiso.info/textos/index.php?id=2092-- (2/09/2014 a les 10.59 h).

4 Junta de Andalucía. La Ciudad viva. Consultat En: http://www.laciudadviva.org/blogs/?p=20126 (2/09/2014 a les $12.00 \mathrm{~h})$.

${ }^{5}$ Hutton, Will. Give us back our públic spaces so we can have access to all areas. Consultat En:

http://www.theguardian.com/commentisfree/2013/jun/16/retail-development-public-access-planning (2/09/2014 a les $11.29 \mathrm{~h})$.

${ }^{6}$ Se puede consultar el proyecto En: $\mathrm{http}: / / \mathrm{www}$.ericparryarchitects.co.uk/projects/working/paternoster-square-london.html (2/09/2014 a les $11.35 \mathrm{~h})$.
} 
La autora cita muchas plazas más que en definitiva tienen un punto en común. A pesar de estar abiertas en la ciudad se comportan como centros comerciales cercados. Su concepción va encaminada a una forma de vida que se resume a comprar o trabajar, de aquí que los usos establecidos sean exclusivamente oficinas, tiendas y restaurantes. La vida diaria de los usuarios ya está programada sin necesidad de pensar en otras opciones o acciones espontáneas. La arquitectura que las rodea es genérica, concebida y construida a gran velocidad, donde el muro cortina y el aire acondicionado es omnipresente, y se acerca a la definición de Ciudad Genérica de Rem Koolhaas. Por otro lado, la libertad que el espacio público ha ofrecido tradicionalmente se queda en estos casos en una promesa, la misma que ofrece el neoliberalismo donde se confunde la libertad personal con la libertad empresarial.

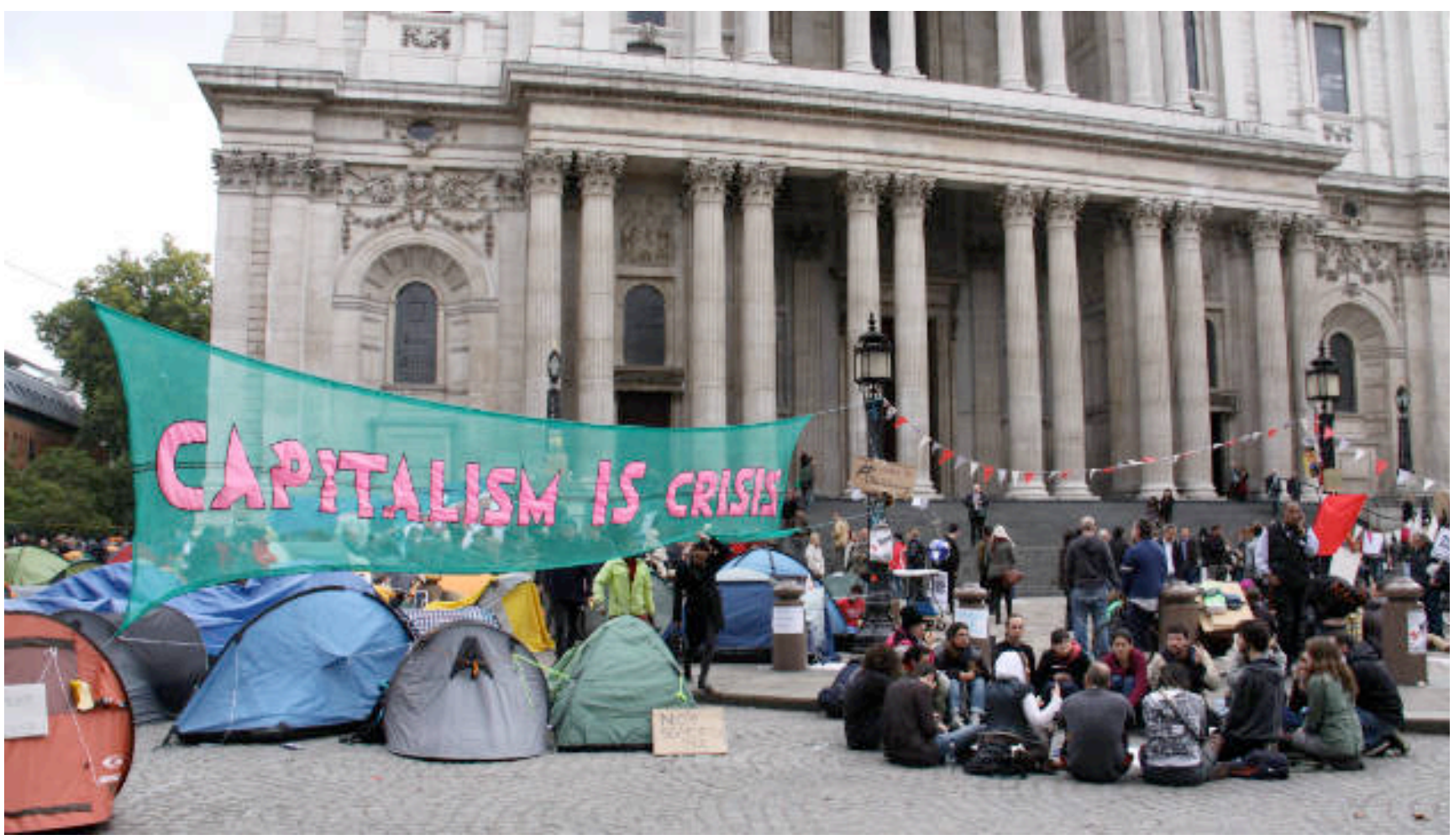

Ilustración 2. La acampada, asambleas y manifestantes de “Occupy London” durante las protestas en la St Paul's Cathedral.

Un caso contrario lo encontramos en la ciudad de Grenoble (Francia). El 26 de noviembre del 2014 apareció un artículo que nos interesó por ser una fórmula, aunque pequeña, de como las ciudades pueden sobrevivir sin publicidad a sus calles. Entre enero y abril del año 2015 se retirarán 326 carteles publicitarios de las calles de la ciudad. En la página web de la alcaldía se puede leer «Grenoble se libera de la publicidad!». La decisión tomada por el Ayuntamiento es la de reemplazar toda la publicidad de las calles por árboles y por tablones de anuncios de la comunidad. El promotor de la iniciativa es el mismo alcalde, Éric Piolle, del partido ecologista y de Los Verdes. Para justificar la decisión, la alcaldía se apoya en las cifras de una encuesta sobre la percepción que los ciudadanos tienen de la publicidad. Concretamente, menciona el estudio del 2013 "Publicidad y sociedad" realizado por la empresa de sondeos de opinión TNS Azufres en Francia. Según esta empresa el $73 \%$ de los encuestados considera que la publicidad es invasiva. Además, argumenta que cada vez es menos efectiva (lo piensa el $65 \%$ de los que participó en la encuesta) y el $45 \%$ dice que tiene cada vez menos capacidad de convicción. Piolle comenta durante la entrevista que es el momento de hacer emerger una ciudad más fresca y creativa. Una ciudad pensada a la medida de los niños y niñas, menos agresiva, menos estresante, al servicio de nuestra creatividad y de nuestra identidad.

\section{Conclusiones.}

Liberar este espacio público supondrá más espacio libre porque las asociaciones culturales y sociales de la ciudad promuevan sus actividades en carteles y tableros. Esto, siendo realistas, también supondría una bajada en la entrada de capital a las arcas municipales de cualquier ayuntamiento. Ocho años antes de que Grenoble, en el 2006, Sao Paulo en Brasil puso en marcha un objetivo similar llamado Ley Ciudad Limpia. La retirada de publicidad reveló la arquitectura original de la ciudad y supuso una revalorización de la construcción de espacios y no el uso de la ciudad meramente como apoyo de comercialización de mercancías.

Un barrio que en las últimas décadas también ha sufirdo un proceso de degradación, intento de destrucción y actualmente se encuentra sujeto a problemáticas vinculadas a la gentrificación es el Cabanyal en Valencia. Es allí donde propusimos una intervención artística que situaba el foco de atención precisamente en estos procesos especulativos de privatización vinculados a la gentrificación llamada 
"Cabanyal 1641". El trabajo presenta una recolección de las casas que iban a ser expropiadas y derruidas en el Cabanyal, una de las luchas vecinales más fervientes que se ha vivido en Valencia desde hace más de una década, y que en la actualidad continua vigente aunque se haya transformado hacia otras cuestiones vinculadas al neoliberalismo. El número se debe a las 1641 viviendas expropiados, y contando con que sólo 1 de cada 3 familias que iban a ser reubicadas en pisos de nueva construcción, conformarían las 533 familias presentes en la escultura. Divididas en 53 casas unifamiliares y 240 viviendas que acogen a dos familias. Con esto construimos una escultura de $180 \mathrm{~cm}$, relativa a escala 1:2000 a la longitud total de la Avenida de Blasco Ibáñez después de la modificación propuesta por PERI, Pla Especial de Reforma Interior, elaborado por AUMSA por encargo del Ayuntamiento de Valencia en época de gobierno del Partido Popular. En la eterna confrontación entre la conservación del patrimonio o el desarrollo especulativo, este plan suponía la destrucción de un conjunto histórico protegido de la ciudad, declarado Bien de Interés Cultural (BIC) en 1993.

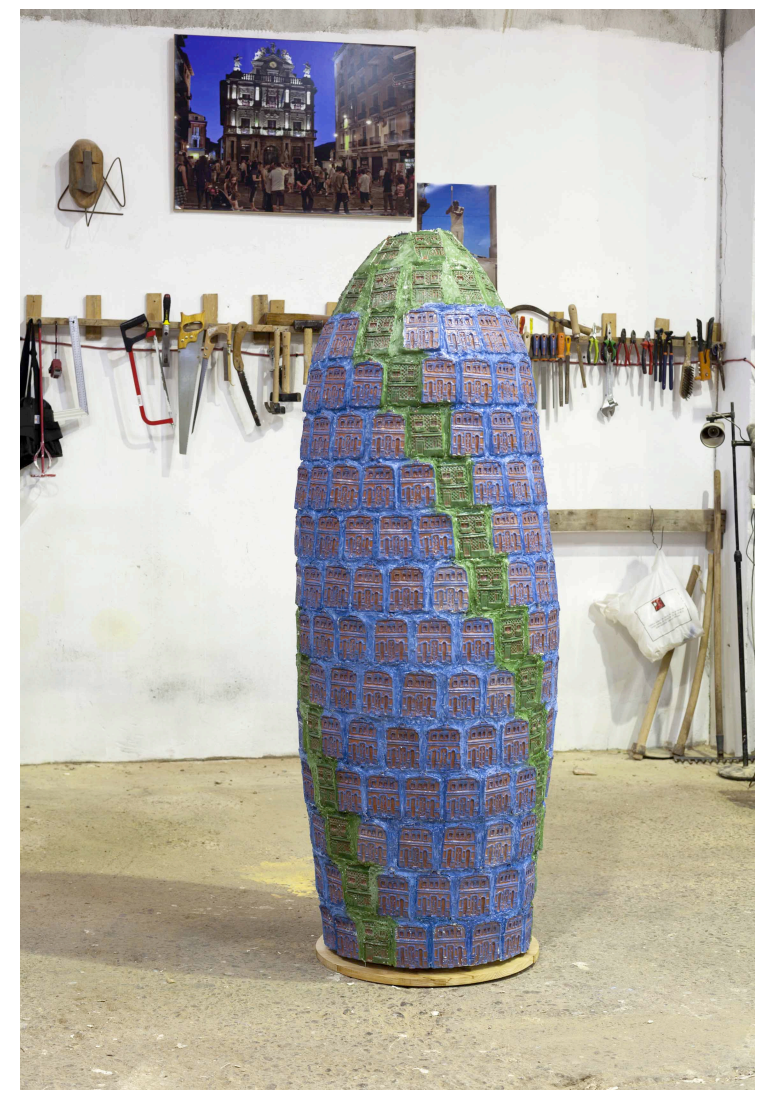

Ilustración 3. Escultura terminada en el taller.

De manera simbólica lo que hicimos es construir una escultura con estas casas expropiadas que se presentan en cubos de cerámica (con estilo de azulejo enladrillado) en dos colores. La idea reside en la proclama «Construye tu propio edificio líder con un barrio histórico!» en referencia al plan del derribo del Cabanyal y la posterior proyección especulativa de la avenida Blasco Ibáñez con la construcción de hoteles y edificios punteros. Construimos una forma de arquitectura in vitro con un barrio histórico, por eso nos hemos basado en el edificio «30 St Mary Axe» de Londres del arquitecto Norman Foster. El edificio, también conocido como «el pepinillo» o "falo de cristal» según diferentes publicaciones en periódicos y revistas londinenses, representa una forma de arquitectura fractal, en espiral, que se vuelve símbolo de los poderes fácticos en los grandes centros financieros a escala mundial. Por tanto lo que hicimos es usar este edificio como icono de la perpetuación del arquitecto en la humanidad y sociedades venideras, sin tener en cuenta un análisis en profundidad relativa a los derechos y deberes del autor (artista(arquitecto) con su entorno y comunidad, que favorece al peligroso concepto de globalización. La creciente pérdida de aquello local a favor de la homogeneización global en todos los procesos derivados de la construcción de un modelo de gestión y desarrollo urbano entorpece la participación ciudadana basada en el debate plural y el compromiso con un desarrollo económico asentado en las bases de aquello local.

Es por eso que planteamos un juego, para darle un nuevo enfoque a esta problemática generada, y así proponer una lectura diferente. Construimos esta escultura y nos la llevamos para ser fotografiada en el mismo barrio, a los solares vacíos que han dejado las antiguas casas ya derruidas. Tenía sentido que las escultura volviese al sitio de donde provenía para generar un diálogo activo con el entorno y sus habitantes demostrando que el arte puede tener una repercusión mucho más social, invitando a la reflexión y suponiendo una manera de intervenir un contexto social de una manera estética. 
El derecho a la ciudad. Transformaciones y resistencias en la ciudad neoliberal

III CONGRESO INTERNACIONAL DE INVESTIGACIÓN EN ARTES VISUALES :: ANIAV 2017 :: GLOCAL [codificar, mediar, transformar, vivir] http://dx.doi.org/10.4995/ANIAV.2017.6418
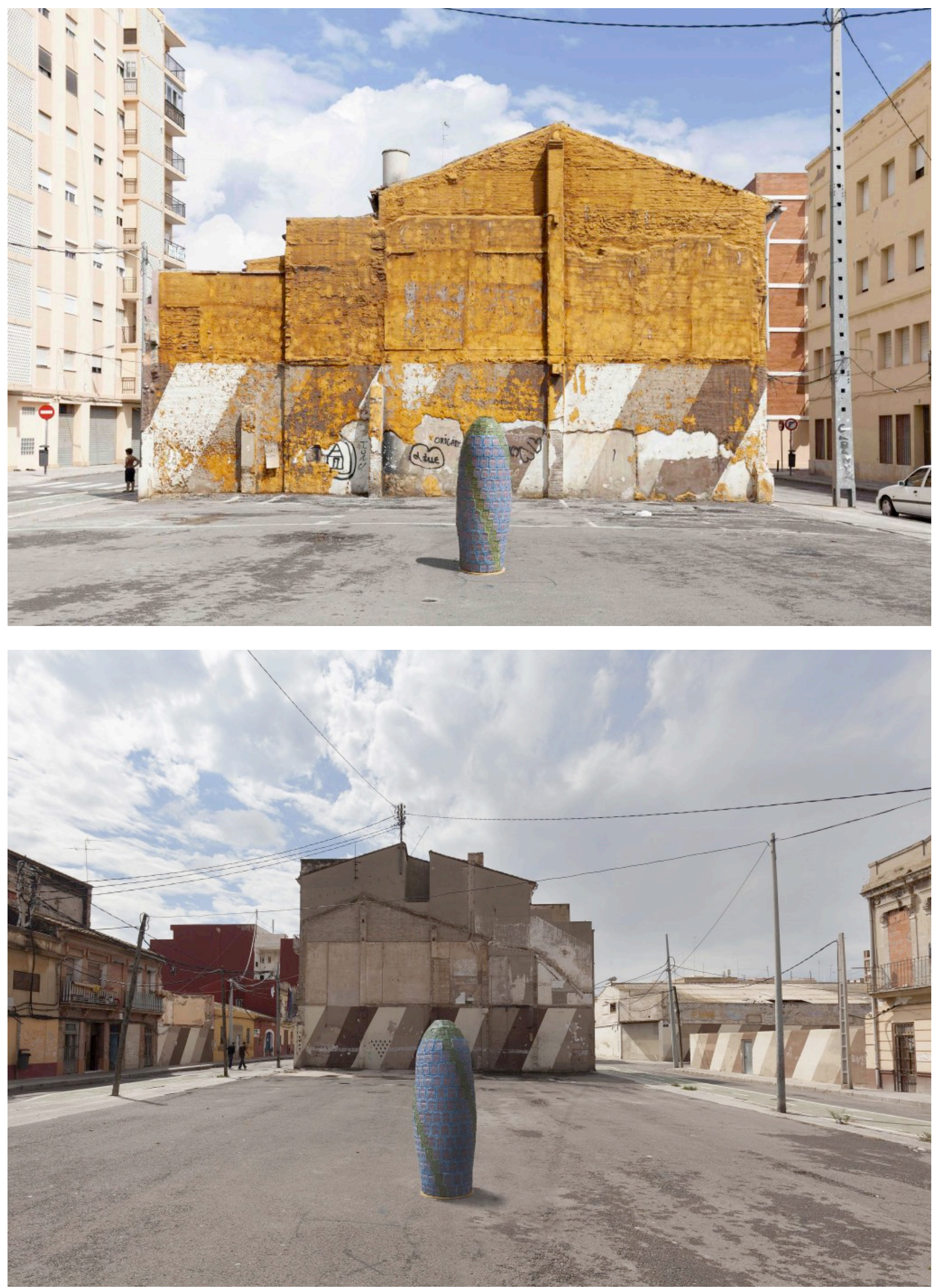

Ilustración 4. Intervención pública de la escultura en el Cabanyal (Valencia). 
Una vez fotografiada ofrecemos el juego en una caja para que los usuarios que quieran participar puedan construirla a escala. A la vez que adoptamos una posición clara, la conservación y rehabilitación del Cabanyal-Canyamelar supone una oportunidad para Valencia de poseer un centro histórico único en Europa que puede convertirse en reclamo turístico a la vez preservar su debilitada identidad. Con ello hay que tomar especial cuidado ya que los procesos de turstificación en las ciudades van ligados a un rechazo vecinal y un desplazamiento de los colectivos más desfavorecidos con los que no nos encontramos de acuerdo. Poner cuidado en estas problemáticas supondrá una solución a un problema en el que ya estamos viendo como no se está trabajando bien. En la actualidad ya se vislumbra como una vez paralizada la ampliación de dicho barrio los procesos de marginación, desplazamiento y elitización están suponiendo enfrentamientos y descontento entre el vecindario que imposibilitan al fin y al cabo el objetivo último que sería construir un barrio habitable hecho para sus vecinos independientemente de su procedencia o de su ideología. Los beneficios a largo plazo pueden ser mucho más beneficiosos que los pretendidos por los intereses económicos del poder. En la capacidad que tengamos de leer y generar nuevos diálogos participativos y abiertos podremos definir un nuevo futuro mejor para el barrio del Cabanyal.

\section{CABANYAL 1641}

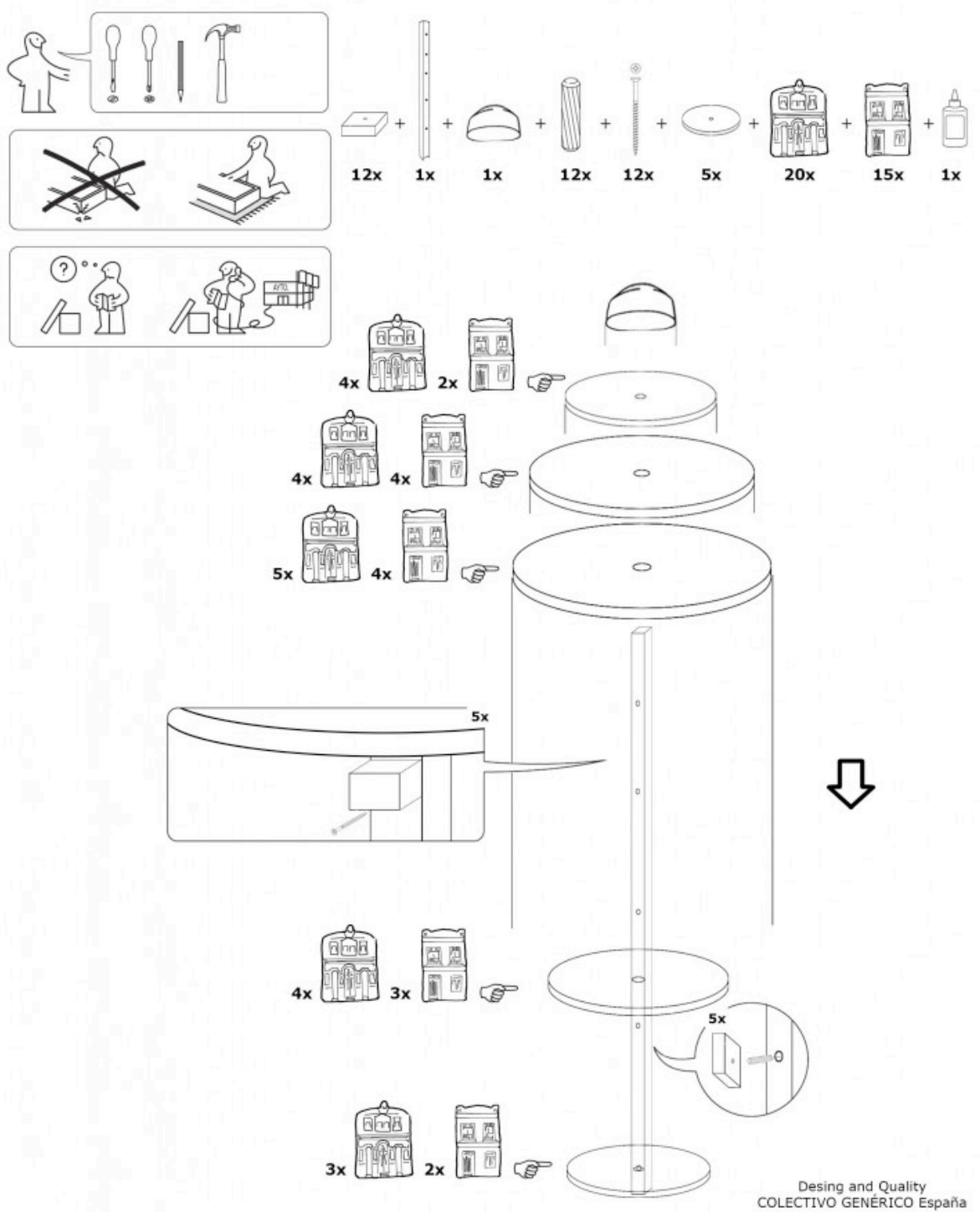

llustración 5. Instrucciones de montaje de la escultura. 


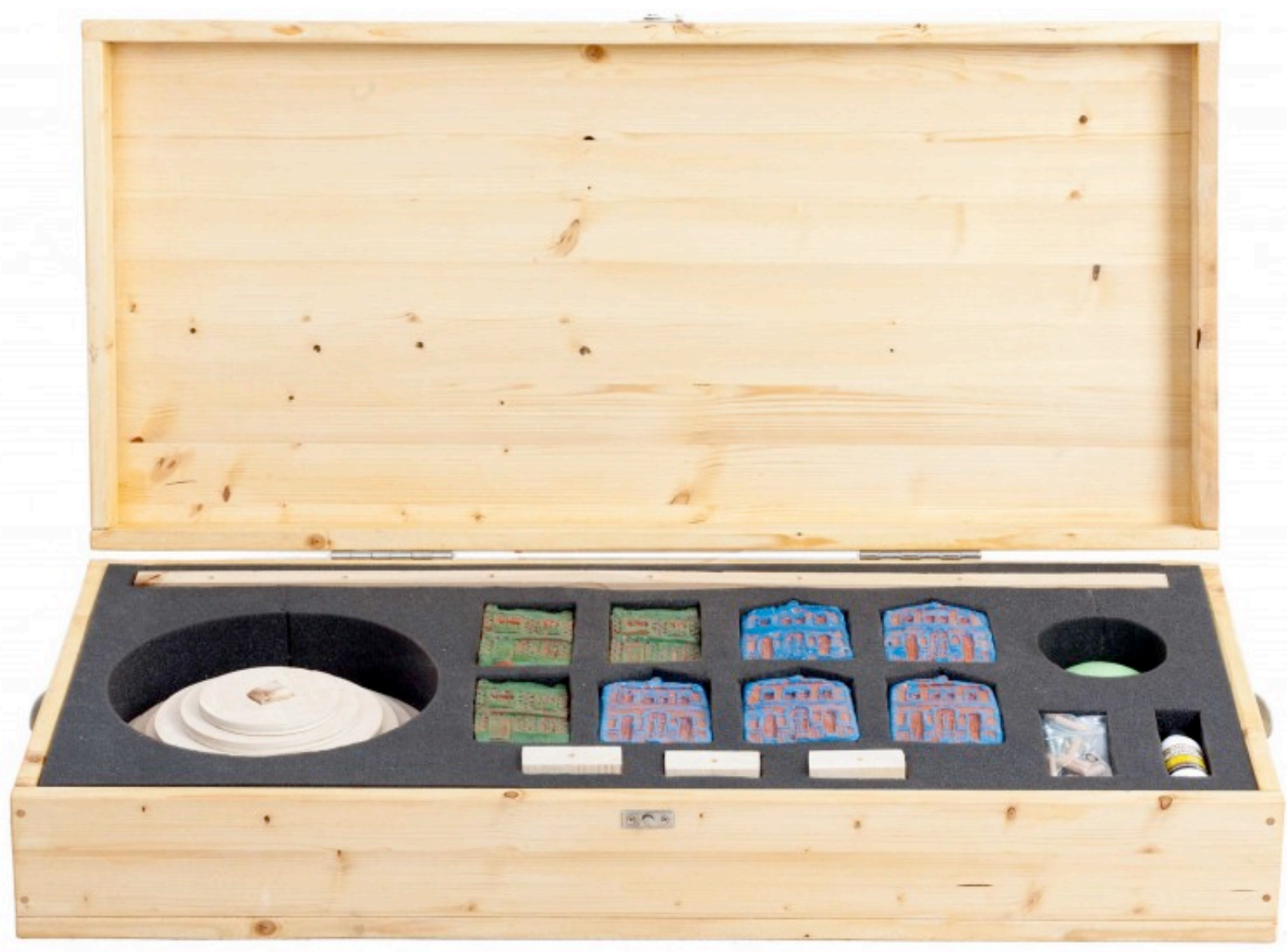

Ilustración 6. Caja con las piezas para montar la escultura "Cabanyal 1641". Construye tu propio edificio puntero con un barrio histórico!. ${ }^{7}$

\section{FUENTES REFERENCIALES.}

Alexander, Jeffrey. Sociología cultural. Formas de clasificación en las sociedades complejas. Anthropos, Barcelona, 2000.

Appadurai, Arjun. La modernidad desbordada. Dimensiones culturales de la globalización. Ed. F.C.E., México, 2001.

Beck, Ulrich. ¿Qué es la globalización? Falacias del globalismo, respuestas a la globalización. Ed. Paidós, Buenos Aires, 1999.

Bourriaud, Nicolas. Estética relacional. Ed. Adriana Hidalgo, Buenos Aires, 2006.

Castells, Manuel. Redes de indignación y esperanza. Ed. Alianza. Madrid, 2012.

${ }^{7}$ Para más información y detalle de tanto esta como otras intervenciones visitar la página web www.danieltomasmarquina.com 

http://dx.doi.org/10.4995/ANIAV.2017.6418

D.A. Modos de hacer. Arte crítico, esfera pública y acción directa. Ediciones Universidad de Salamanca, Salamanca, 2001.

D.A. Querido público. El espectador ante la participación: jugadores, usuarios, prosumers y fans. Ed. CENDEAC, Murcia, 2009.

Duque, Félix. Arte público y espacio político. Ediciones Akal, Madrid, 2001.

García Canclini, Néstor. Cultura y desarrollo. Ed. Paidós. Barcelona 2012.

Harvey, David. El derecho a la Ciudad. Revista Sin Permiso, 05/10/2008 En: International Journal of Urban and Regional Research, vol. 27 , № 4 .

Harvey, David. Ciudades Rebeldes. Del derecho de la ciudad a la revolución urbana. Ed. Akal, Madrid, 2013.

Hutton, Will. Give us back our públic spaces so we can have access to all areas. The Gaurdian Press, 16/06/2013.

Jameson, Frederic. El postmodernismo o la lógica cultural del capitalismo avanzado. Ed. Paidós, Barcelona, 1991.

Junta de Andalucía. La Ciudad viva. Web del ayuntamiento, 26/04/2017.

Rifkin, Jeremy. La era del acceso. La revolución de la nueva economía. Ed. Paidós, Buenos Aires, 2000.

Rowan, J. Cultura libre de Estado. Ed. Traficantes de sueños. Madrid, 2016.

W. soja, Edward. Postmetrópolis. Estudios críticos sobre las ciudades y las regiones. Ed. Traficantes de Sueños. Madrid, 2008. 